http://jmscr.igmpublication.org/home/ ISSN (e)-2347-176x ISSN (p) 2455-0450

crossref DOI: https://dx.doi.org/10.18535/jmscr/v8i10.08

\author{
Journal Of Medical Science And Clinical Research \\ IGM Publication \\ An Official Publication of IGM Publication
}

\title{
Dry Eye in Pterygium and Post Pterygium Surgery- A Clinical Study
}

\author{
Authors \\ Dr Ambika S Patil ${ }^{1}$, Dr Sanjeev M Patil ${ }^{2}$ \\ ${ }^{1}$ MS Ophthalmology, Assistant Professor, MRMC, KALABURAGI \\ ${ }^{2}$ MS General Surgery, Associate Professor, MRMC, KALABURAGI
}

\begin{abstract}
Background and Objectives: pterygium is a common extraocular disease, seen in tropical countries like India. Pterygium is an elevated, triangular, fibrovascular encroachment of bulbar conjunctiva on to the cornea. A small pterygium usually gives rise to no symptoms. But, if large can be quite bothersome cosmetically, induce astigmatism or cause impair vision. But the most common symptoms are irritation, watering, foreign body sensation due to dry eye. Surgical removal of pterygium with Autoconjunctival graft or with $0.02 \%$ Mitomycin-C for 2 minutesremains the mainstay of treatment. Hence this study is conducted to know the relation between dry eye and pterygium, and also to know the reliable test for dry eye in pterygium \& post pterygium surgery.

Methods: The present prospective randomized clinical trial was conducted at Basaveshwar Teaching \& General Hospital, Gulbarga, over a period of two years. In the study, 80 eyes of 80 patients were included after detailed preoperative evaluation. After informed written consent, they were randomized into two groups to receive either conjunctival autograft or Intraoperative application of $0.02 \%$ Mitomycin- $C$ for 2 minutes, following excision of pterygium. Tear breakup time [BUT], schirmer's test-1 and schirmer's test-2 were done in all 80 eyes preoperatively and after 2months post-pterygium excision surgery. 80 cases completed the study.

Results and Observations: The majority of patients were in the age group 40-49 years(37.50\%).Mean age of the patients was 44.133 years. 45 (56.25\%) patients had bilateral pterygium and 35 cases were unilateral(43.75\%). 76 cases(95\%) were primary pterygium and 4(5\%) cases were recurrent pterygium.51.9\% of the patients with primary pterygium had occupations involving predominantly outdoor activity.

Of 80 cases, 51 patients (63.75\%) were positive with Schirmer's test I, 49 patients(61.25\%) with Schirmer's test II and 52 patients(65\%) with TBUT, preoperatively. 44 patient (55\%) were positive with Schirmer's test I, 41 patients (51.25\%) with Schirmer's test II, 14 patients (17.5\%) with TBUT, postoperatively.

Conclusion: From the present study, we conclude that pterygium causes unstable tear film causing dry eye. Tear film abnormality improves after pterygium excision surgery with Autoconjunctival graft or with $0.02 \%$ Mitomycin-C for 2minutes. Both the methods were safe.

Further TBUT was more reliable test than schirmer's test in assessing the correlation between dry eye in pterygium and post pterygium excision surgery.
\end{abstract}

\section{Aim}

1) To assess the correlation between dry eye and pterygium.

2) To evaluate the reliable test for dry eye in pterygium and post- pterygium excision surgery.

\section{Methodology}

Source of Data: All the cases undergoing pterygium excision surgery at Basaveshwar Teaching \& General Hospital attached to M.R. Medical College, Gulbarga.

Study Design: Prospective randomized clinical trial. 


\section{Sample Size: 80 Cases}

This study included 80 eyes of 80 patients who visited the Department of Ophthalmology with significant complaints related to pterygium. The total sample size was 80 .

\section{Inclusion Criteria}

- All patients with progressive pterygium who are willing for pterygium excision surgery.

\section{Exclusion Criteria}

- Patients with history of autoimmune diseases, uncontrolled diabetes mellitus, conditions with poor wound healing, pregnant, lactating women and other systemic diseases.

- Patients with uveitis, corneal ulcer, scleritis, episcleritis, glaucoma.

- Patients with pseudopterygium.

\section{Preoperative Evaluation}

- History

- Visual Acuity recording

- Refraction

- Slit Lamp Examination

- Staining

- Tear film tests - (1) Schirmer's test-I (2)Shirmer's test-II and (3) Tear film breakup time (TBUT)

- Anterior segment photography

- Fundus examination

- Keratometry

The anterior segment was examined with special attention to the tear film for dry eye. Lid abnormalities and other conditions predisposing to poor wound healing. Evaluation of lens and thereafter fundus examination was done to rule out any posterior segment pathology responsible for diminution of vision. The extent of pterygium was measured from limbus to corneal encroachment by using slit lamp beam directed horizontally and vertically and the vascularity of the pterygium was noted.

\section{Investigations}

- $\mathrm{CBC}$

- Urine routine

- ESR

- RBS
- HIV

- $\mathrm{HBs} A g$

Method: After taking informed written consent, selected cases will be randomly allotted into groups A and B,40 each.

Group A, where conjunctival autografting after bare sclera excision; Group B, where application of $0.02 \%$ mitomycin-c for 2 minutes, following bare sclera excision of pterygium.

After meeting the inclusion and exclusion criteria, patients were worked up thoroughly, as under: Detailed history of symptoms were recorded. General physical examination was done. Thorough ophthalmic examination were done. Tests for dry eye were done as under:

\section{Tear film break up time (TBUT)}

Cornea was stained with flourescein and the patient was examined in slit lamp under blue filter illumination. The time interval between the appearance of first dry spot on the tear film and the opening of eyelids was recorded. Three such recordings were done and the average was taken as TBUT. TBUT, if less than 10 seconds, the test was considered positive.

\section{Schirmer's test}

1) Schirmer's test I (without anaesthesia)

2) Schirmer's test II (with anaesthesia). The patient was made to sit in dim lighted room, the schirmer's strip was folded at the notch and was placed over the lower palpebral conjunctiva at the junction of lateral $1 / 3$ and medial $2 / 3$. The patient was asked to look straight, to keep eyes open and to blink normally. After 5 mins the strip was removed and the amount of wetting was recorded in millimeters. If the reading was less than $10 \mathrm{~mm}$ at the end of $5 \mathrm{mins}$, the schirmer's test I was considered positive.

The schirmer's test II was performed in similar way after instillation of anaesthetic drug $4 \%$ xylocaine topically.

The schirmer's strip used was Whatmann filter paper no.41, measuring $35 \times 5 \mathrm{~mm}$ and was folded $5 \mathrm{~mm}$ from one end. 


\section{Surgical Procedure}

\section{Preoperative Preparation}

Anaesthesia-Peribulbar anaesthesia given.

- Cleaning and draping of the Surgical field. Preparation included using $10 \%$ povidineiodine to clean the skin area cleanse followed by adequate draping.

- All surgeries were performed using an operating microscope.

- A wire speculum was used to separate the lids. A superior rectus bridle suture put using 4-0 black silk.

\section{Bare Sclera (D'Ombrain's) Technique}

The basic technique involved in the study is the Bare sclera method of Pterygium excision.

The head of the pterygium is dissected from cornea by tenting the pterygium apex with fine forceps. The conjunctiva is progressively dissected from the body of the pterygium using Westcott's scissors. The process was completed towards the upper fornix, caruncle and lower fornix in the shape of a triangle with its apex at the limbus, avoiding any conjunctival buttonholing.

The corneal epithelium $2 \mathrm{~mm}$ ahead of the head of pterygium was scraped off with a Tooke's knife. The pterygium head is easily avulsed using a combination of blunt dissection with crescent and traction.

The body of the pterygium with the involved Tenon's Capsule and cicatrix was then excised taking care not to damage the underlying medial rectus muscle. The abnormal tissue at the limbal end of pterygium was resected, extending $2-3 \mathrm{~mm}$ beyond the visible extent of pterygium, to have a good bed for placement of the graft. Wetfield cautery is used to cauterize bleeding vessels as necessary.

\section{Conjunctival Autograft technique}

The first step is the Bare Sclera method of Excision.

The bridle suture was used to rotate the globe downwards exposing the superior limbus and conjunctival surface. A conjunctival graft required to resurface the exposed scleral surface was excised from superior bulbar conjunctiva.

The limbus was smoothened using crescent. Using a Westcott's scissors the graft was excised. After excision, the conjunctival autograft was slid and moved onto the bare sclera with non-toothed forceps and sutured with 10-0 nylon interrupted sutures. The graft was smoothened out in its bed. The four corners of the graft were anchored with episcleral bites to maintain position. The medial edge of the graft was sutured with 2-4 additional sutures, preferably including episclera.

At the end of the surgery, the eye was patched firmly after application of antibiotic ointment.

\section{Intra operative Mitomycin C}

Again the basic procedure is the Bare sclera method of pterygium excision.

\section{Preparation of Mitomyin C solution}

Mitomycin $\mathrm{C}$ is available as Crystalline Mitomycin $\mathrm{C}$ for injection. The vial contains $2 \mathrm{mg}$ of crystalline Mitomycin $\mathrm{C}$ and $9.8 \mathrm{mg}$ of $\mathrm{NaCl}$. When 1 vial of $2 \mathrm{mg}$ preparation is dissolved in $10 \mathrm{ml}$ of distilled water the concentration of Mitomycin C $0.02 \%(0.2 \mathrm{mg} / \mathrm{ml})$ was attained. Once the preparation was ready, it could be used for a maximum period of 1 week, with storage in refrigeration, avoiding exposure to light.

\section{Intraoperative Application}

After the Bare sclera excision of the pterygium, the patient received Mitomycin C $0.02 \%$.A sterile sponge $5 \times 5 \mathrm{~mm}$ soaked in $0.02 \%(0.2 \mathrm{mg} / \mathrm{ml})$ solution of Mitomycin $\mathrm{C}$ was placed on the bare sclera for 2 minutes. Care was taken so that the pledget did not come in contact with cornea. After removal of sponge, the application site was thoroughly irrigated with $20-30 \mathrm{ml}$ of BSS solution.

Eyes were patched with antibiotic ointment application. 


\section{Postoperative advice}

In both the groups, postoperatively topical antibiotic-steroid eye drops (Ofloxacin \& Dexamethasone) were used every 2 hours for the first postoperative week and then tapered over the next 4 weeks. Lubricant ointment - Lacrigel (1\% HPMC) was applied twice a day. Sutures were removed after one week.

\section{Postoperative Follow up}

Patients will be followed up post operatively on Day 1, 1 week, 1 month, 2 months, 6 months and one year to evaluate the results. At every follow up patients will be assessed and the following parameters recorded-symptomatic improvement, visual acuity, any adverse effect of the drug, any surgical complications, cosmetic appearance and finally post operative recurrence. On 2 months of postoperative follow up, tests for dry eye- TBUT, Schirmer's test-I and Schirmer's test-II were done.

\section{Results}

80 patients were included in our study. They were randomly assigned to either Group A or Group B. 40 patients in Group A underwent Bare Sclera Excision technique followed by Conjunctival Autograft. 40 patients in Group B underwent Bare Sclera Excision followed by Intraoperative Application of $0.02 \%$ Mitomycin-C for two minutes.

Table-1: Randomization

\begin{tabular}{||l|c|c|}
\hline Groups & No. of Patients & Percentage \\
\hline Group A & 40 & $50 \%$ \\
\hline Group B & 40 & $50 \%$ \\
\hline
\end{tabular}

Out of total patients who completed the $\operatorname{study}(80)$ after randomization, 40 patients belonged to Group A who underwent Conjunctival autograft technique and 40 patients to Group B, who underwent Intraoperative Application of $0.02 \%$ Mitomycin $\mathrm{C}$ for two minutes following Bare sclera excision.

Table-2: Age Incidence

\begin{tabular}{||c|c|c|c|c||}
\hline Age(Yr) & Group A & Group B & Total & Percentage \\
\hline $20-29$ & 1 & 5 & 6 & $7.5 \%$ \\
\hline $30-39$ & 4 & 5 & 9 & $11.25 \%$ \\
\hline $40-49$ & 16 & 14 & 30 & $37.5 \%$ \\
\hline $50-59$ & 8 & 8 & 15 & $20 \%$ \\
\hline $60-69$ & 9 & 7 & 16 & $20 \%$ \\
\hline $70-79$ & 2 & 1 & 5 & $3.75 \%$ \\
\hline
\end{tabular}

$\mathrm{Z}=1.45$, $\mathrm{p}$ value $>0.05$ (not significant).

Out of 80 cases, 30 eyes $(37.5 \%)$ belonged to patients in the age group 40-49 years, 15 (20\%) eyes belonged to the age group 50-59 years, 9 eyes(11.25\%) belonged to the age group 30-39 years, 16 eyes $(20 \%)$ to $60-69$ years age group, 6 eyes $(7.5 \%)$ belonged to $20-29$ year age group and $3(3.75 \%)$ to the age group $70-79$ years. 
Table-3: Sex Incidence

\begin{tabular}{||l|c|c|c|c|}
\hline Gender & Group A & Group B & Total & Percentage \\
\hline Males & 21 & 20 & 41 & $51.25 \%$ \\
\hline Females & 19 & 20 & 39 & $48.75 \%$ \\
\hline
\end{tabular}

Out of 80 patients, $41(51.25 \%)$ were males and $39(48.75 \%)$ were females.
In Group A, there were 21 males (52.5\%) and 19 females $(47.5 \%)$. In Group B, there were 20 males $(50 \%)$ and 20 females (50\%).

Table 4: Correlation of dry eye in pterygium and post surgery

\begin{tabular}{||l|c|c|c|c|c|c||}
\hline Dry eye tests & \multicolumn{7}{|c||}{ Schirmer's test II } & \multicolumn{2}{|c|}{ TBUT } \\
\hline & \multicolumn{2}{|c|}{ Schirmer's test I } & \multicolumn{1}{|c||}{ Sch } \\
\hline & (n) & $\%$ & (n) & $\%$ & (n) & $\%$ \\
\hline preoperative & 51 & $63.75 \%$ & 49 & $61.25 \%$ & 52 & $65 \%$ \\
\hline postoperative & 44 & $55 \%$ & 41 & $51.25 \%$ & 14 & $17.5 \%$ \\
\hline
\end{tabular}

Of 80 cases, 51 patients $(63.75 \%)$ were positive with Schirmer's test I, 49 patients $(61.25 \%)$ with Schirmer's test II and 52 patients (65\%) with TBUT, preoperatively. 44 patients (55\%) were positive with Schirmer's test I, 41 patients (51.25\%) with Schirmer's test II, 14 patients(17.5\%) with TBUT, postoperatively.

Table-5: In Conjunctival Autograft

\begin{tabular}{||l|c|c|c|c|c|c||}
\hline \multirow{2}{*}{} & \multicolumn{2}{|c|}{ Schirmer's test I } & Schirmer's test II & \multicolumn{2}{c|}{ TBUT } \\
\cline { 2 - 7 } & No. & Percent & No. & Percent & No. & Percent \\
\hline Preoperative & 24 & $60 \%$ & 21 & $52.5 \%$ & 26 & $65 \%$ \\
\hline Postoperative & 19 & $47.5 \%$ & 16 & $40 \%$ & 5 & $12.5 \%$ \\
\hline
\end{tabular}

Out of 40 patients in group-A, 24 patients $(60 \%)$ were positive with Schirmer's test I, 21 patients $(52.5 \%)$ with Schirmer's test II and 26 patients (65\%) with TBUT, preoperatively. 19 patients
(47.5\%) were positive with Schirmer's test I, 16 Patients (40\%) with Schirmer's test II and 5 (12.5\%) were positive with TBUT, postoperatively.

Table-6: In Mitomycin C

\begin{tabular}{||l|c|c|c|c|c|c||}
\hline \multirow{2}{*}{} & \multicolumn{2}{|c|}{ Schirmer's test I } & Schirmer's test II & \multicolumn{2}{c|}{ TBUT } \\
\cline { 2 - 7 } & No. & Percent & No. & Percent & No. & Percent \\
\hline Preoperative & 27 & $67.5 \%$ & 28 & $70 \%$ & 26 & $65 \%$ \\
\hline Postoperative & 25 & $62.5 \%$ & 25 & $62.5 \%$ & 9 & $22.5 \%$ \\
\hline
\end{tabular}

Out of 40 patients in group-B, 27 patients $(67.5 \%)$ were positive with Schirmer's test I,28 patients (70\%) with Schirmer's test II and 26 patients $(65 \%)$ with BUT, preoperatively. 25 patients
(62.5\%) were positive with Schirmer's test I, 25 patients $(62.5 \%)$ with Schirmer's test II and 9 $(22.5 \%)$ were positive with TBUT, postoperatively. 


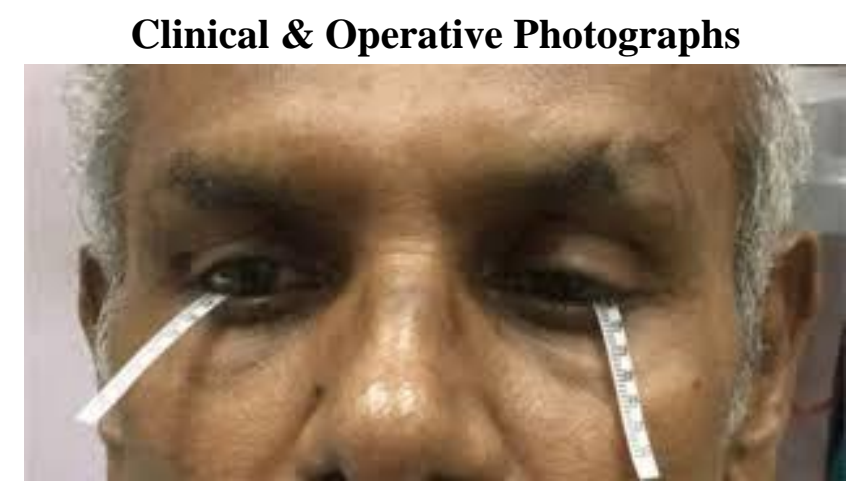

Schirmer's test

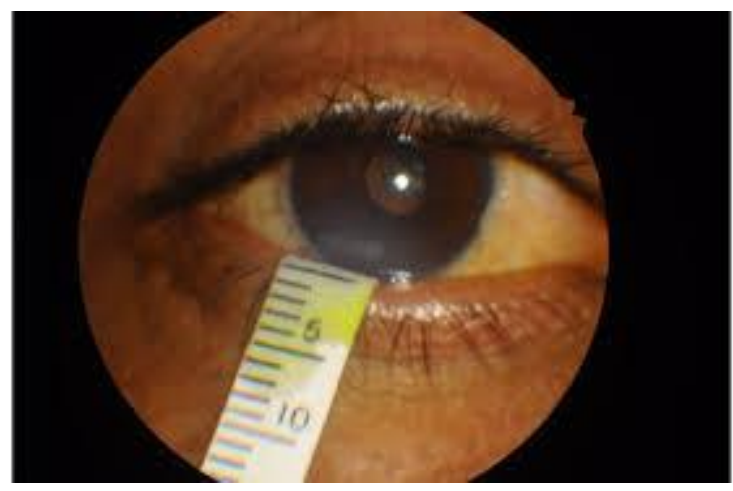

Schirmer's test

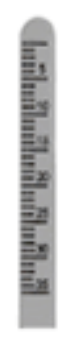

Schirmer's strip

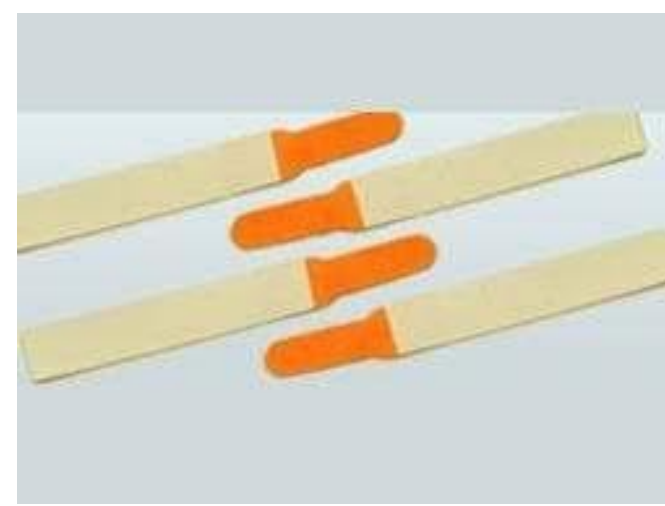

Flourescein strip

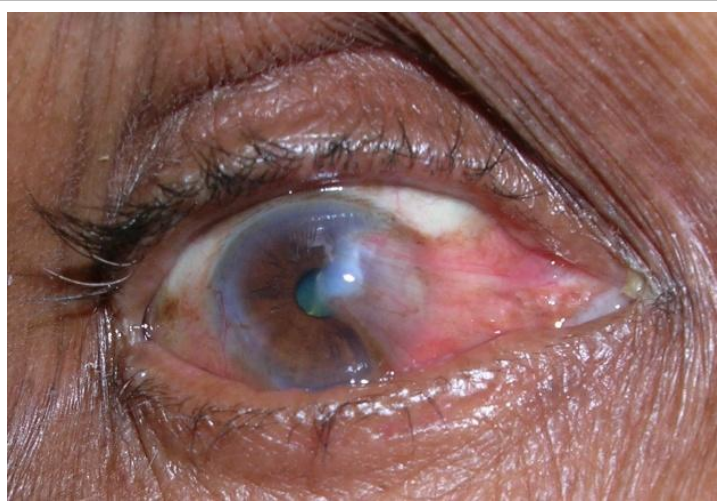

Grade-III Pterygium

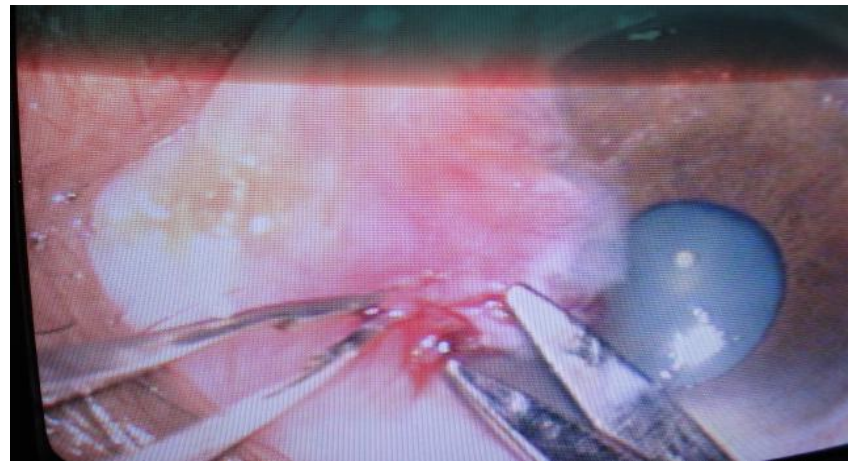

Excision of Head of Pterygium

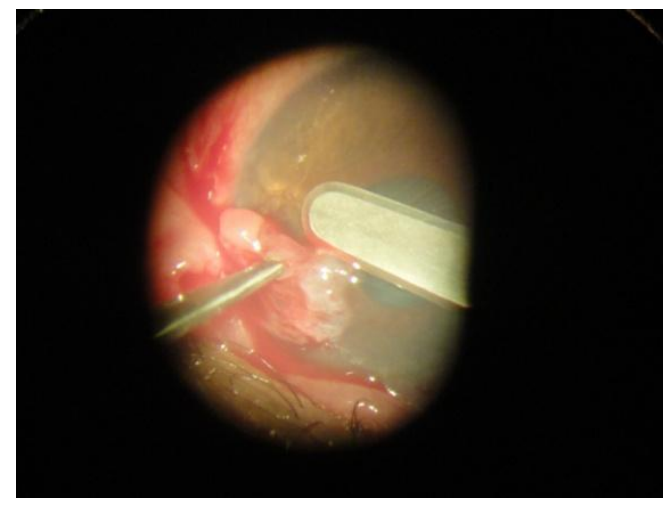

Blunt dissection with crescent

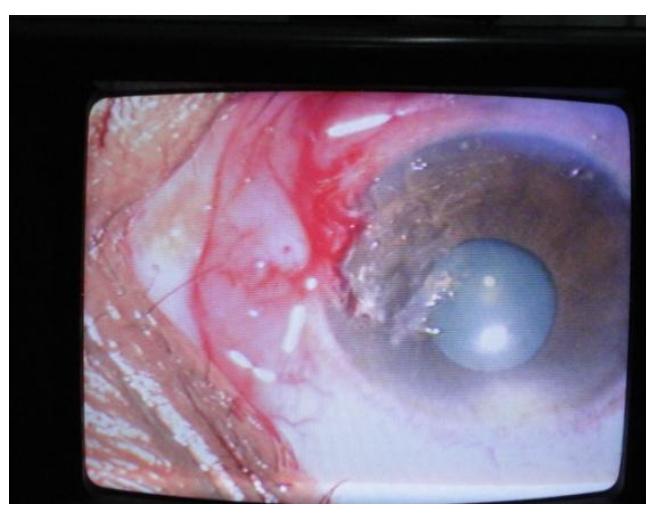

After excision of head and body of pterygium 


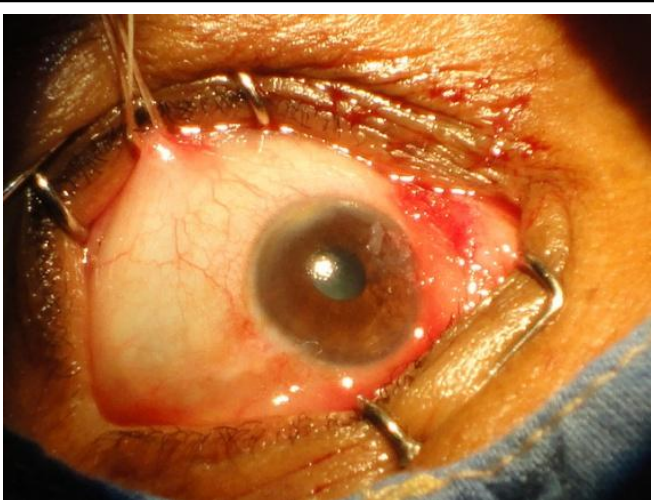

Bare Sclera

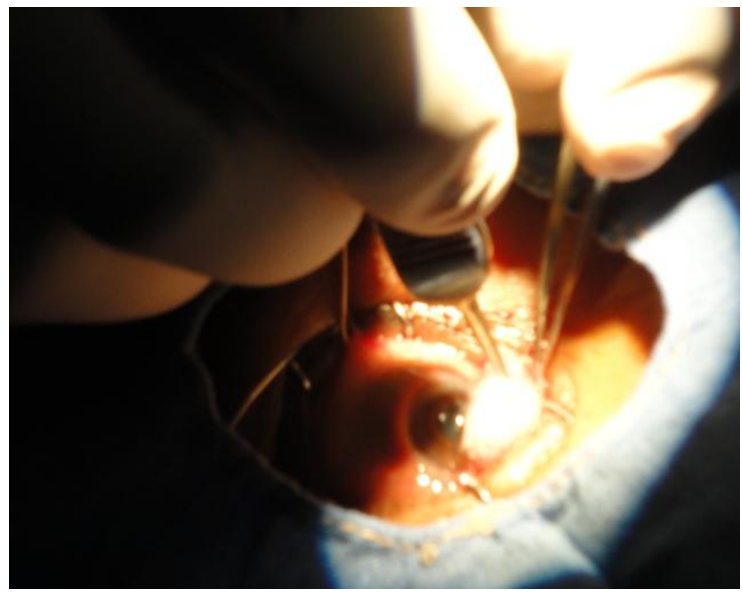

Application of mitomycin-C $\mathbf{0 . 0 2 \%}$

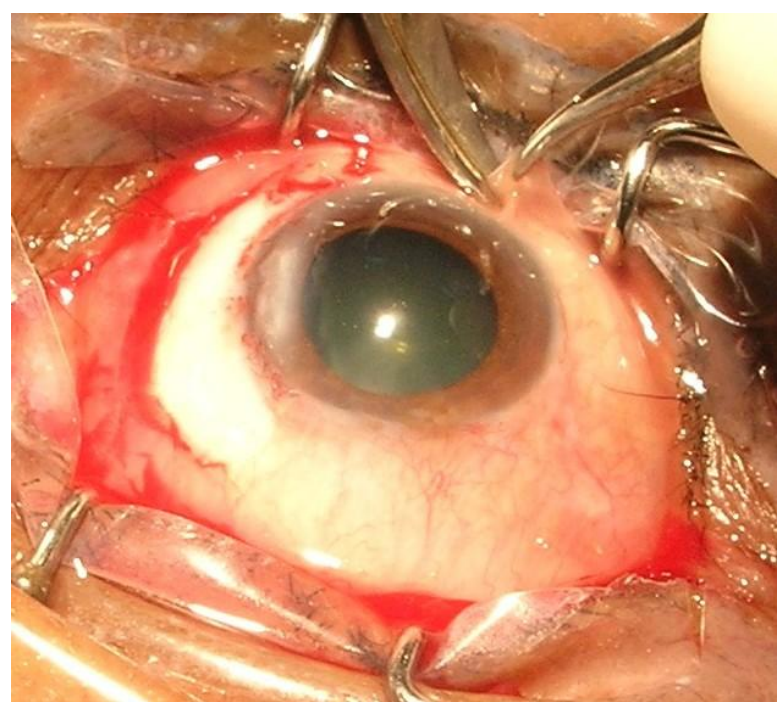

Excision of superior bulbar conjunctival graft
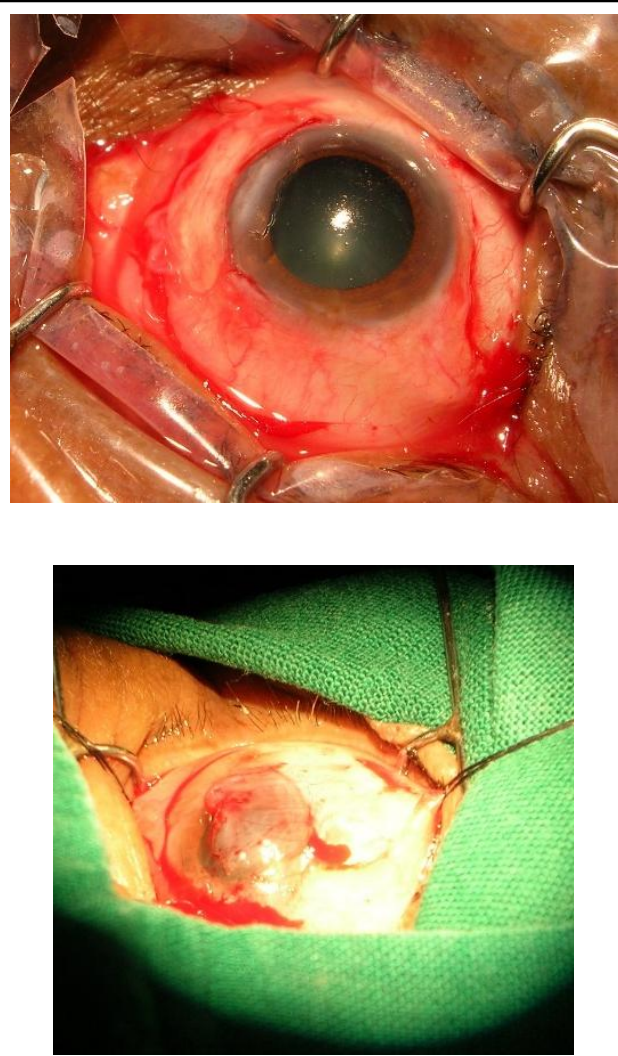

Placement of graft on bare sclera

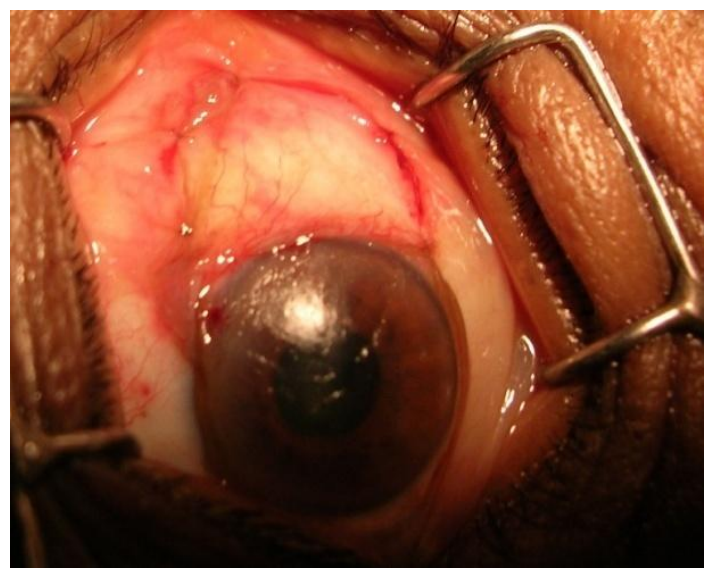

Sutured graft

\section{Discussion}

Pterygium is a common external ocular disease seen in tropical countries like India. This study was conducted to know the relation between pterygium and dry eye and to know the reliability of dry eye tests in pterygium and post pterygium excision surgery with Auto-conjunctival graft/ with $0.02 \%$ Mitomycin-C for 2 mins.

80 patients included in our study completed it. They were randomly assigned to either Group A or Group B. 40 patients in Group A underwent Bare Sclera Excision technique followed by Auto- 
conjunctival graft. 40 patients in Group B underwent Bare Sclera Excision followed by Intraoperative Application of $0.02 \%$ Mitomycin-C for two minutes. Dry eye tests TBUT, Schirmer's test I, Schirmer's test II were done in all 80 patients preoperatively and after 2 months postoperatively.

\section{Age Distribution}

- In our study ages of patients ranged from 2075 years. The highest number of patients were in the Age group 40-49 years (37.5\%).Lowest number of cases were in the age group70-79 years $(3.75 \%)$

\section{Sex Distribution}

- In our study, number of males included is $41(51.25 \%)$ and females were 39 in number (48.75\%). However the dominance of male sex is not statistically significant ( $p$ value $>0.05$ )

\section{Laterality}

Of the 80 patients in our study, $45(56.25 \%)$ patients had Bilateral pterygium and 35(43.75\%) cases were unilateral.

\section{Location}

- In our study pterygium was located nasally in 79 cases and in 1 case both temporally and nasally located with a mean pre-operative encroachment of $3.2 \mathrm{~mm}$.

\section{Type of Pterygium}

- Of the 80 cases, $76(95 \%)$ were primary pterygium and $4(5 \%)$ cases were recurrent pterygium. However this distribution of primary and recurrent pterygia is not statistically significant ( $p>0.05$ ).

6. Effect of Occupation of Individual on Pterygium

- In our study, 41 patients with primary pterygium (51.9\%)were engaged in occupations involving predominantly outdoor activity. 35 patients with primary pterygium $(43.75 \%)$ were involved in indoor work, the influence of outdoor activity was not considered statistically significant ( $\mathrm{p}$ value $>0.05$ ).
7. Complaints: In our study the most frequent complaint given by the patient was fleshy growth, dry eye symptoms like ocular irritation and watering followed by redness and defective vision.

\section{Results}

Out of 80 patients, 51 patients were positive with Schirmer's test I, 49 patients with Schirmer's test II and 52 patients with BUT preoperatively. 44 patients were positive with Schirmer's test I, 41 patients with Schirmer's test II and 14 patients with BUT postoperatively. Hence pterygium causes dry eye, and also there was significant difference in BUT preoperatively and postoperatively. Hence, BUT is more reliable test for pterygium with dry eye.

\section{Conclusion}

From the present study, we conclude that pterygium causes unstable tear film leading to dry eye. Tear film abnormality improves after pterygium excision surgery with autoconjunctival graft or with $0.02 \%$ Mitomycin-C for 2 minutes. Both methods were safe.

Further, TBUT was more reliable than Schirmer's test in assessing the correlation between dry eye in pterygium and post pterygium excision.

\section{Bibliography}

1. Ombrain A. The surgical treatment of pterygium. Br J Ophthalmology 1948; 32: 65-7.

2. Hirst LW, Sebban A, Chant D. Pterygium Recurrence time. Ophthalmology 1994; 101:755-8.

3. Tan DH, Chee SP, Dear KBG.Effect of pterygium morphology on pterygium recurrence in a controlled trial comparing conjunctival autografting with bare sclera excision. Arch Ophthalmol 1997;115: 1235-40.

4. Moran DJ, Hollows FC. Pterygium and ultraviolet radiation: A positive 
correlation. Brit J Ophthalmology 1984; $68: 343$

5. Detels R, SP Dhir. Pterygium: A geographical study. Arch Ophthalmology 196 Oct; 78 (4) : 485.

6. Zauberman H. Pterygium and its recurrence. Am J Ophthalmol 1967 Jun; 63 (6): 1780.

7. Adamis AP, Starck T, Kenyon KR.The management of pterygium. Ophthalmol Clin North Am 1990; 3(4):611.

8. Taylor HR, West SK, Rosenthal FS. Corneal changes associated with chronic UV irradiation. Arch Ophthalmol 1989; 107:1481.

9. Jose I Barraquer. Etiopathogenesis and treatment of pterygium. Symposium on Medical and Surgical Diseases of Cornea 1980; 533-40.

10. Rosenthal JW. Chronology of pterygium therapy. Am J Ophthalmol 1953; 36: 1601.

11. Zolli CL. Experience with the avulsion technique in pterygium surgery. Ann Ophthalmol 1979; 11:1569.

12. Gibson JBC. Brisbane surgery of pterygium. Trans Ophthalmol Soc Aust 1956; 16:125.

13. Kenyon KR, Wagoner MD, Hettinger ME. Conjunctival autograft transplantation for advanced and recurrent pterygium. Ophthalmology 1985; 92:1461.

14. Sharma A, Gupta A, Ram J. Low-dose intraoperative mitomycin-C versus conjunctival autograft in primary pterygium surgery: long term follow-up. Ophthalmic Surg Lasers 2000 Jul-Aug; 31(4) : 301-7.

15. Tseng SCG. Concept and application of limbal stem cells. Eye 1989; 3:141.

16. Koranyi G, Sexgard S. Cut and paste: a no suture, small incision approach to pterygium surgery. Br J Ophthalmol2004; 88 : 911-914.
17. Sugar HS. A surgical treatment for pterygium based on new concepts to its nature. American Journal of Ophthalmology 1949 July; 32 (7): 912.

18. Arffa RC. Degenerations, In Arffa RC (ed): Grayson's Diseases of the Cornea, 3rd ed, CV Mosby, St. Louis ,1991 ; 342. 